\title{
Statistical Analysis of C-H Activation by Transition Metal Oxo Spe- cies Supports Thermodynamic Control Over Reactivity
}

\author{
Joseph E. Schneider, McKenna K. Goetz, and John S. Anderson* \\ Department of Chemistry, University of Chicago, Chicago, IL 60637, USA
}

\begin{abstract}
Transition metal oxo species are key intermediates for the activation of strong $\mathrm{C}-\mathrm{H}$ bonds. As such, there has been interest in understanding which structural or electronic parameters of metal oxo complexes determine their reactivity. Factors such as ground state thermodynamics, spin state, steric environment, oxygen radical character, and asynchronicity have all been cited as key contributors, yet there is no consensus on when each of these parameters is significant or the relative magnitude of their effects. Herein, we present a thorough statistical analysis of parameters that have been proposed to influence transition metal oxo mediated C-H activation. We used density functional theory (DFT) to compute parameters for transition metal oxo complexes and analyzed their ability to explain and predict an extensive data set of experimentally determined reaction barriers. We found that, in general, only thermodynamic parameters related to the free energy of hydrogen atom, proton, and electron transfer play a statistically significant role.
\end{abstract}

\section{INTRODUCTION}

The activation of $\mathrm{C}-\mathrm{H}$ bonds through proton-coupled electron transfer (PCET) underpins a wide range of biological and synthetic processes. The applications of this reaction include drug metabolism by cytochrome P450 enzymes as well as synthetic methods for the preparation of fine chemicals. ${ }^{1-3}$ In many cases PCET reactions are mediated by transition metal oxo intermediates generated within either protein based or synthetic ligand scaffolds. In these reactions, both a proton and an electron are transferred to an oxo complex resulting in the net removal of a hydrogen atom from the organic substrate. The generality of this reaction combined with the ubiquity of $\mathrm{C}-\mathrm{H}$ bonds in synthesis has led to considerable interest in determining what properties govern the PCET reactivity of transition metal oxo species.

A large body of work supports that the free energy of reaction $\left(\Delta \mathrm{GPCET}_{\mathrm{T}}\right)$ is central to transition metal oxo mediated $\mathrm{C}-\mathrm{H}$ activation and also offers a great deal of explanatory and predictive power. ${ }^{4-7}$ However, additional properties have recently been cited as important, notably 0-centered spin density, ${ }^{8}$ spin state, ${ }^{9-11}$ steric environment, ${ }^{12-14}$ the free energies of proton and electron transfer $\left(\Delta \mathrm{G}_{\mathrm{PT}}\right.$ and $\left.\Delta \mathrm{G}_{\mathrm{ET}}\right),{ }^{15-}$ 20 and the asynchronicity $(\eta)$ of the reaction (Scheme 1$).{ }^{21-}$ ${ }^{24}$ While individual cases support the influence of these characteristics on the rate, mechanism, and selectivity of C$\mathrm{H}$ activation reactions, there is a lack of consensus regarding their generality and relative importance. ${ }^{8,25}$ Very few studies have explored these parameters outside of a narrow range of complexes, $4,6,10,20,21,26$ and none have statistically examined the significance of parameters other than $\Delta$ GPCET on the reactivity of a broad set of metal oxo complexes.

We previously found an atypical dependence on $\Delta \mathrm{G}_{\mathrm{PT}}$ in the concerted $\mathrm{C}-\mathrm{H}$ activation reactivity of a terminal $\mathrm{Co}^{\mathrm{III}}$ oxo complex which contrasts with the more commonly observed rate dependence on $\Delta$ Gрсет. ${ }^{15}$ Given the disparity of this result with the literature, we sought to understand the interplay of characteristics affecting a broad range of transition metal oxo mediated PCET reactions using multivariable linear free energy relationships (LFERs). These models can be used to relate experimentally determined data, such as reaction rates, to multiple predictor variables simultaneously. LFER models have recently been used as versatile tools to optimize organic methodology, predict reaction barrier heights, and investigate underlying mechanisms. ${ }^{27-}$ 31

We have applied this analysis to examine trends in rates of PCET mediated C- $\mathrm{H}$ activation for a broad dataset of previously reported metal oxo complexes. This analysis

Scheme 1. Investigated Parameters of Metal Oxo Species.

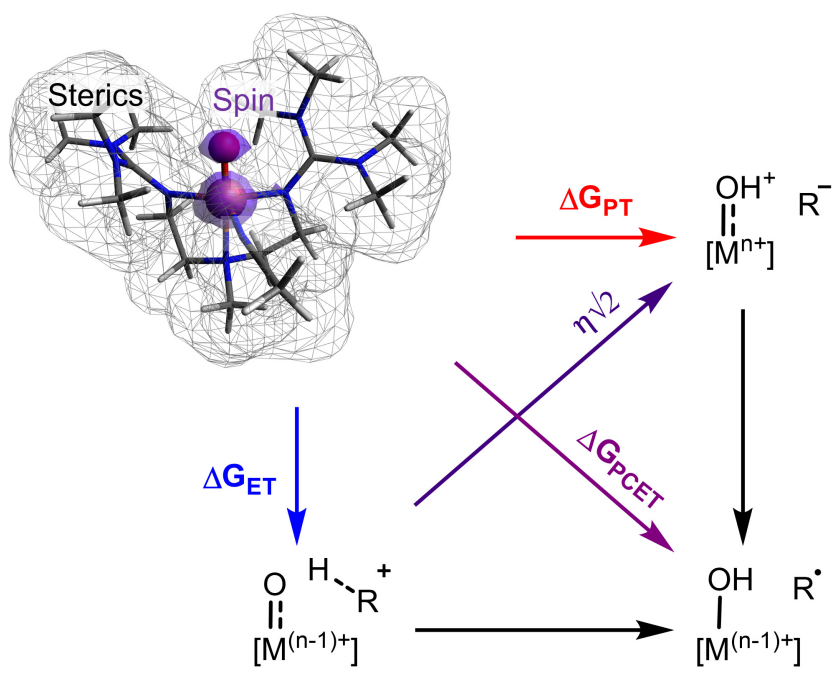


Table 1. Statistical Results of Various Models.

\begin{tabular}{|c|c|c|c|c|c|}
\hline \multirow{2}{*}{$\begin{array}{c}\text { Parameter }(\mathrm{s}) \\
\text { Regressed with } \Delta \text { GPCET }\end{array}$} & \multicolumn{3}{|c|}{ Training Set on $\mathrm{DHA}^{a}$} & \multicolumn{2}{|c|}{ All Data for Multiple Substrates $b$} \\
\hline & $\mathrm{R}^{2}$ & $\mathrm{LOO}^{c} \mathrm{R}^{2}$ & p-value ${ }^{d}$ & $\mathrm{R}^{2}$ & $\mathrm{LOO}^{e} \mathrm{R}^{2}$ \\
\hline$\Delta \mathrm{GPCET}_{\mathrm{P}}$ only & 0.70 & 0.60 & $<0.001^{f}$ & 0.55 & 0.50 \\
\hline$\% B V$ Steric Metrics & 0.77 & 0.64 & 0.15 & 0.58 & 0.43 \\
\hline Oxo Spin Density & 0.70 & 0.55 & 0.78 & 0.62 & 0.51 \\
\hline Spin Excitation & 0.71 & 0.50 & 0.49 & 0.59 & 0.52 \\
\hline$|\eta|$ & 0.73 & 0.53 & 0.22 & 0.60 & 0.49 \\
\hline$\Delta \mathrm{GPT}_{\mathrm{PT}} \Delta \mathrm{G}_{\mathrm{ET}}$ & 0.86 & 0.71 & $\begin{array}{c}0.0082 \\
0.023^{g} \\
0.0038^{h}\end{array}$ & 0.69 & 0.56 \\
\hline
\end{tabular}

${ }^{a}$ A subset of the reactions of 17 metal oxo complexes with DHA. ${ }^{b}$ Excluding outlier metal oxo complexes $\left(\mathrm{Ru}^{\mathrm{IV}}\right.$ oxos and oxo complexes of 13-TMC); substrates are DHA, 1,4-cyclohexadiene, xanthene, and fluorene. ${ }^{c}$ Leave-One-Out. $d$ From an F-test where the null hypothesis is that only $\Delta$ GPCET has an effect. $e$ Leave-One-Out, slightly modified such that all reactions for a given metal oxo are left out together. $f$ From an F-test where the null hypothesis is that $\Delta \mathrm{G}_{\text {PCET }}$ has no effect. $g$ From an F-test where the null hypothesis is that $\Delta \mathrm{GPT}_{\mathrm{PT}}$ has no effect. $h$ From an F-test where the null hypothesis is that $\Delta \mathrm{G}_{\mathrm{ET}}$ has no effect.

enables a statistical examination of several hypotheses regarding what parameters of metal oxo species determine their PCET reactivity. We have found that while $\Delta \mathrm{G}_{\mathrm{PCET}}$ is the most important factor for determining reactivity, $\Delta \mathrm{GPT}_{\mathrm{PT}}$ and $\Delta \mathrm{G}_{\mathrm{ET}}$ also play statistically significant roles. Interestingly, the other parameters investigated do not have broad significance, although they may be important in specific cases.

\section{RESULTS AND DISCUSSION}

We began our analysis by compiling an extensive data set of second order rate constants $\left(k_{2}\right)$ for the oxidation of 9,10dihydroanthracene (DHA) by 28 well-characterized metal oxo complexes. ${ }^{12,13,15,17,32-47}$ This diverse data set comprises complexes of five different transition metals, tetragonal and trigonal geometries, spin multiplicities from 1 to 5 , charges from -1 to +3 , and d-electron counts from 0 to 6 . We manually divided the data set into a training set of seventeen metal oxo complexes and a test set of eleven metal oxo complexes such that each set had a diverse mix of species. For our analysis, we calculated the values of parameters that have been hypothesized as important to metal oxo mediated PCET reactivity for each metal oxo complex. The investigated parameters include the steric environment (quantified by percent buried volume, $\% \mathrm{BV}),{ }^{48}$ the spin density on the oxygen atom (via intrinsic bond order (IBO) analysis), ${ }^{49,50}$ the energetic cost of accessing a higher spin state if one lies closer to the product spin multiplicity than the reactant ground spin state (spin excitation), the thermodynamic free energies $\Delta \mathrm{GPCET}_{\mathrm{P}} \Delta \mathrm{G}_{\mathrm{PT}}$, and $\Delta \mathrm{G}_{\mathrm{ET}}$, and the magnitude of the asynchronicity parameter $(|\eta|) .^{21}$ The detailed approaches used to determine the values for these parameters is provided in the methods section.

We examined the effect of each of these parameters on experimental reaction barriers by building multivariable free energy models via ordinary least squares regression of the barrier heights against the parameters. These models were used to generate predicted reaction barriers for each data point, which could be compared with experimental reaction barriers to assess the utility of the model. Because

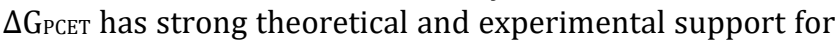
affecting reaction barrier heights, ${ }^{4-6}$ we analyzed each parameter in combination with $\Delta \mathrm{GPCET}$ and compared the resulting model to regression against $\Delta \mathrm{G}_{\text {PCET }}$ alone.
We evaluated each regression based on $\mathrm{R}^{2}$, leave-one-out (LO0) $\mathrm{R}^{2}$ (sometimes referred to as $\mathrm{Q}^{2}$ ), and a statistical Ftest. ${ }^{51-54} \mathrm{R}^{2}$ is a goodness of fit measure which quantifies the amount of variation explained by a model. The predictive ability of a model is gauged with LOO $\mathrm{R}^{2}$, in which each data point is left out and predicted by the remaining data points and the goodness of fit is then reevaluated. Overfitted models perform poorly with this metric. For each $\mathrm{R}^{2}$, a value close to 1 indicates a good fit. Finally, we report the $p$-value from an F-test on each model, which shows the probability the observed correlation arises from statistical noise. The lower this $p$-value is, the more significant a given parameter.

A summary of our findings is presented in Table 1. In line with previous reports, we find a strong correlation between the experimental reaction barriers and $\Delta \mathrm{G}_{\text {PCET. }}$ This parameter alone explains $70 \%$ of the variation in reaction barriers within the training set $\left(\mathrm{R}^{2}=0.70\right)$ and has high predictive ability (LOO $\left.\mathrm{R}^{2}=0.60\right)$. Interestingly, most other parameters do not significantly improve the model. While we do observe a small correlation with \%BV steric metrics, the magnitude of the effect is too small to be statistically significant. Compared to the $\Delta$ GPCET only model, spin-based parameters and $|\eta|$ barely improve $\mathrm{R}^{2}$ and perform similarly or worse in LOO cross-validation. While it is difficult to rule out the importance of these parameters in individual cases, an F-test indicates they do not have a statistically significant effect across our entire data set.

In contrast, addition of $\Delta \mathrm{G}_{\mathrm{PT}}$ and $\Delta \mathrm{G}_{\mathrm{ET}}$ does significantly improve the fit. For this $\left\{\Delta \mathrm{G}_{\mathrm{PCET}}, \Delta \mathrm{G}_{\mathrm{PT}}, \Delta \mathrm{G}_{\mathrm{ET}}\right\}$ model, $\mathrm{R}^{2}$ increases from 0.70 to 0.86 and LOO $\mathrm{R}^{2}$ increases from 0.60 to 0.71 , indicating both better explanation of the available data and better predictive ability. An F-test gives $\mathrm{p}<0.01$ which suggests the observed effect is statistically significant. The equation from this fit is $\Delta \mathrm{G}^{\ddagger}=0.31 \Delta \mathrm{GPCET}+0.07 \Delta \mathrm{GPT}_{\mathrm{PT}}+0.12$ $\Delta \mathrm{G}_{\mathrm{ET}}-0.26$ (all coefficients unitless; free energies and intercept in $\mathrm{kcal} / \mathrm{mol}$ ). Each coefficient is positive: the more negative $\Delta \mathrm{G}_{\mathrm{PCET}}$ or the less positive $\Delta \mathrm{G}_{\mathrm{PT}}$ and $\Delta \mathrm{G}_{\mathrm{ET}}$, the lower the reaction barrier. The larger coefficient of $\Delta \mathrm{G}_{\text {PCET }}$ indicates the reaction barrier is most sensitive to this free energy. Satisfyingly, the $\Delta \mathrm{G}_{\text {PCET }}$ coefficient agrees with experimental data: for metal oxo complexes that have a demonstrated trend of $\log \left(k_{\mathrm{obs}}\right)$ vs. substrate BDFE, the average slope of 
$\Delta \mathrm{G}^{\ddagger}$ vs. substrate BDFE is $\sim 0.3$ (see Table S1), very similar to the 0.31 observed in our analysis.

The significance of $\Delta \mathrm{G}_{\mathrm{PT}}$ and $\Delta \mathrm{G}_{\mathrm{ET}}$ is intriguing because the literature discussion of these values has often been framed in terms of how they contribute to $\Delta$ GPCET rather than in terms of their intrinsic contribution to reaction barrier heights. ${ }^{16-19}$ These parameters are distinguished from $\Delta$ GPCET by the fact that $\Delta$ GPCET contains the free energy of initial electron or proton transfer and the free energy of subsequent transfer of the other component of an $\mathrm{H}$-atom to form a full thermodynamic cycle. In contrast, $\Delta \mathrm{GPT}_{\mathrm{PT}}$ and $\Delta \mathrm{G}_{\mathrm{ET}}$ as defined here, are the energies to form the initial intermediates involved in such an analysis - the protonated metal oxo with the deprotonated substrate, or the reduced metal oxo with the oxidized substrate - and thus do not form a full thermodynamic cycle with $\Delta \mathrm{G}_{\mathrm{PCET}}$. Therefore, $\Delta \mathrm{G}_{\mathrm{PT}}$ and $\Delta \mathrm{G}_{\mathrm{ET}}$ are independent of $\Delta \mathrm{GPCET}$ which is supported by the poor correlations between $\Delta \mathrm{G}_{\mathrm{PCET}}$ and $\Delta \mathrm{G}_{\mathrm{PT}}$ and between $\Delta \mathrm{G}_{\mathrm{PCET}}$ and $\Delta \mathrm{G}_{\mathrm{ET}}(-0.12$ and 0.31 , respectively, see Regression $\mathrm{S} 6)$. We find these additional free energies have importance independent of a contribution to $\Delta \mathrm{G}_{\mathrm{PCET}}$ as clearly demonstrated by the LOO R ${ }^{2}$ s and F-tests.

Assigning a direct role for $\Delta \mathrm{G}_{\mathrm{PT}}$ and $\Delta \mathrm{G}_{\mathrm{ET}}$ is in line with recent computational studies of PCET transition states which invoke off- $\Delta \mathrm{G}_{\text {PCET }}$ diagonal thermodynamic terms from Scheme 1, such as asynchronicity ( $\eta$ ), as key contributors to DFT derived reaction barriers. ${ }^{21-24}$ Asynchronicity is derived not from the sum of $\Delta \mathrm{G}_{\mathrm{PT}}$ and $\Delta \mathrm{G}_{\mathrm{ET}}$, but rather their difference. Conversely, we instead find that the sum of $\Delta \mathrm{GPT}_{\mathrm{PT}}$ and $\Delta \mathrm{G}_{\mathrm{ET}}$ have a larger effect than $|\eta|$. The reason for this discrepancy is unclear, but a possible explanation is that experimental noise prevents us from observing a comparatively more subtle trend between $|\eta|$ and the experimental reaction barrier heights. Furthermore, the well-controlled nature of the series of complexes previously investigated for asynchronicity may have too little variation in $\left(\Delta \mathrm{G}_{\mathrm{PT}}+\Delta \mathrm{G}_{\mathrm{ET}}\right)$ to observe the effect we observe here. Regardless, previous studies as well as this current work offer increasing support that off- $\Delta$ GPCET diagonal thermodynamic terms such as $\Delta \mathrm{G}_{\mathrm{PT}}$ and $\Delta \mathrm{G}_{\mathrm{ET}}$ have important effects on reactivity independent of $\Delta$ GPCET.

The all-thermodynamic model we find here provides insights and possible alternative explanations for previously reported trends in PCET reactivity. In one study, ${ }^{12}$ steric and spin state effects were invoked to explain the comparatively high reactivity of the $S=2$ complex $\left[\mathrm{Fe}^{\mathrm{IV}}(\mathrm{O})\left(\mathrm{TMG}_{2} \text { dien }\right)\left(\mathrm{CH}_{3} \mathrm{CN}\right)\right]^{2+}$. A higher rate of $\mathrm{C}-\mathrm{H}$ activation as compared to $S=2\left[\mathrm{Fe}^{\mathrm{IV}}(\mathrm{O})\left(\mathrm{TMG}_{3} \text { tren }\right)\right]^{2+}$ was ascribed to reduced steric hinderance in the $\mathrm{TMG}_{2}$ dien complex, ${ }^{13}$ and the higher rate of $\mathrm{C}-\mathrm{H}$ activation as compared to the $S=1$ complexes $\left[\mathrm{Fe}^{\mathrm{IV}}(\mathrm{O})(\mathrm{N} 4 \mathrm{Py})\right]^{2+}$ and $\left[\mathrm{Fe}^{\mathrm{IV}}(\mathrm{O})(\mathrm{TMC})\left(\mathrm{CH}_{3} \mathrm{CN}\right)\right]^{2+}$ was ascribed to the $S=2$ spin state in the $\mathrm{TMG}_{2}$ dien complex. ${ }^{34,42}$ However, it was noted that the even faster reactivity of $\left[\mathrm{Fe}^{\mathrm{IV}}(\mathrm{O})\left(\mathrm{Me}_{3} \mathrm{NTB}, \mathrm{CH}_{3} \mathrm{CN}\right)\right]^{2+}$, which is $S=1$ and has a similar $\% \mathrm{BV}$ profile to $\left[\mathrm{Fe}^{\mathrm{IV}}(\mathrm{O})\left(\mathrm{TMG}_{2} \text { dien }\right)\left(\mathrm{CH}_{3} \mathrm{CN}\right)\right]^{2+}, 32$ is not easily explained by either hypothesis. Our analysis suggests that the thermodynamic properties of these complexes may provide an alternative explanation in all four comparisons (see Table S4). The $\mathrm{Me}_{3} \mathrm{NTB}$ complex has by far the most exergonic reaction with DHA $(\Delta \mathrm{GPCET}=-16 \mathrm{kcal} / \mathrm{mol})$, followed by the $\mathrm{TMG}_{2}$ dien complex $\left(\Delta \mathrm{G}_{\mathrm{PCET}}=-9 \mathrm{kcal} / \mathrm{mol}\right)$, followed by the complexes of $\mathrm{TMG}_{3}$ tren, TMC, and N4Py $\left(\Delta \mathrm{G}_{\text {PCET }}=-7,-6\right.$, and $-6 \mathrm{kcal} / \mathrm{mol}$, respectively $)$. Thus, thermodynamic parameters would predict the $\mathrm{Me}_{3}$ NTB complex to have the lowest reaction barrier and fastest rate of reaction, with the $\mathrm{TMG}_{2}$ dien complex being the next most reactive, and the remaining complexes the least reactive as is observed experimentally.

In another study, it was observed that the rates of PCET reactions performed by $\left[\mathrm{Fe}^{\mathrm{IV}}(\mathrm{O})(\mathrm{TMC})(\mathrm{X})\right]^{\mathrm{n}+}$ decrease with more strongly donating axial ligands $\mathrm{X} .{ }^{34}$ Variation in $\Delta \mathrm{GPCET}$ was ruled out as a cause of this trend, as it was calculated to be similar for all complexes investigated. It was suggested that the accessibility of a high-spin state may explain this variation in the rate, as the energy of the quintet excited state decreased with stronger X ligands. However, our calculations indicate that while stronger axial donors increase $\Delta \mathrm{G}_{\mathrm{ET}}, \Delta \mathrm{G}_{\mathrm{PT}}$ decreases more substantially (see Table S4). In our model, these changes result in a net decrease in the reaction barrier, suggesting that despite a similar $\Delta \mathrm{G}_{\mathrm{PCET}}$, the reactivity trend could be explained by thermodynamic effects. These analyses do not rule out that spin state or steric effects may be important in the previous studies, but suggest that thermodynamics may also play an important role.

The fit of the training data to $\left\{\Delta \mathrm{G}_{\mathrm{PCET}}, \Delta \mathrm{G}_{\mathrm{PT}}, \Delta \mathrm{G}_{\mathrm{ET}}\right\}$ and this model's performance on the test set is depicted graphically in Figure 1. It is clear that the reaction barriers for most metal oxo complexes in the test set are well predicted. This includes successful extrapolation to the reaction barriers for $\mathrm{Cr}^{\mathrm{IV}}$ and $\mathrm{Ru}^{\mathrm{VI}}$ oxo examples. ${ }^{40,41}$ Nonetheless, several metal oxo complexes (boxed in the figure) deserve further discussion.

The model behaves the most poorly in predicting reaction barriers for the $\mathrm{Fe}^{\mathrm{IV}}$ oxo and $\mathrm{Co}^{\mathrm{IV}}$ oxo complexes of the

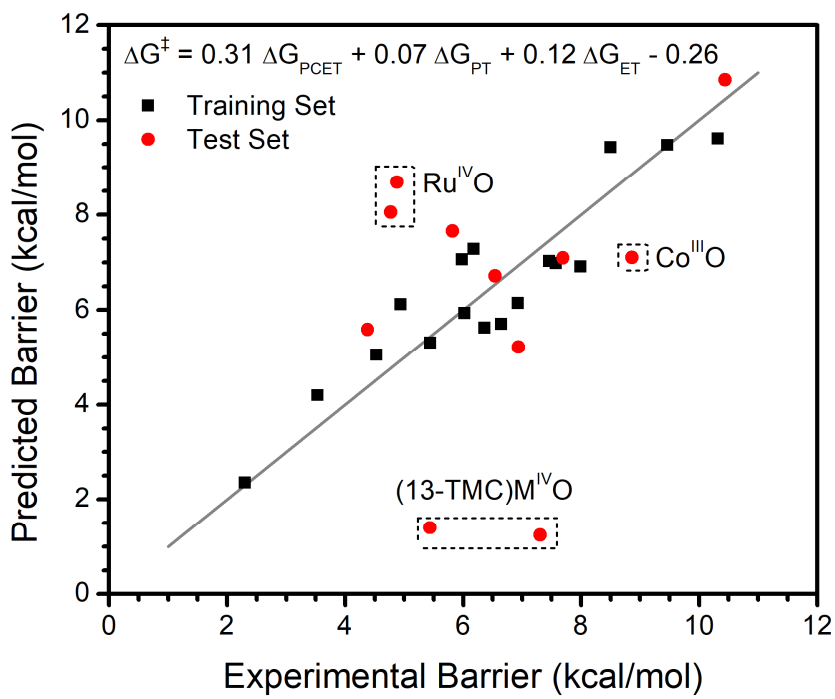

Figure 1. Regression analysis of the experimental reaction barrier vs. $\Delta \mathrm{G}_{\mathrm{PCET}}, \Delta \mathrm{G}_{\mathrm{PT}}$, and $\Delta \mathrm{G}_{\mathrm{ET}}$ for various metal oxo complexes reacting with DHA. Specific cases discussed in the main text are boxed and labeled. The grey line marks where predicted equals experimental. Predicted values are computed using the given formula. 


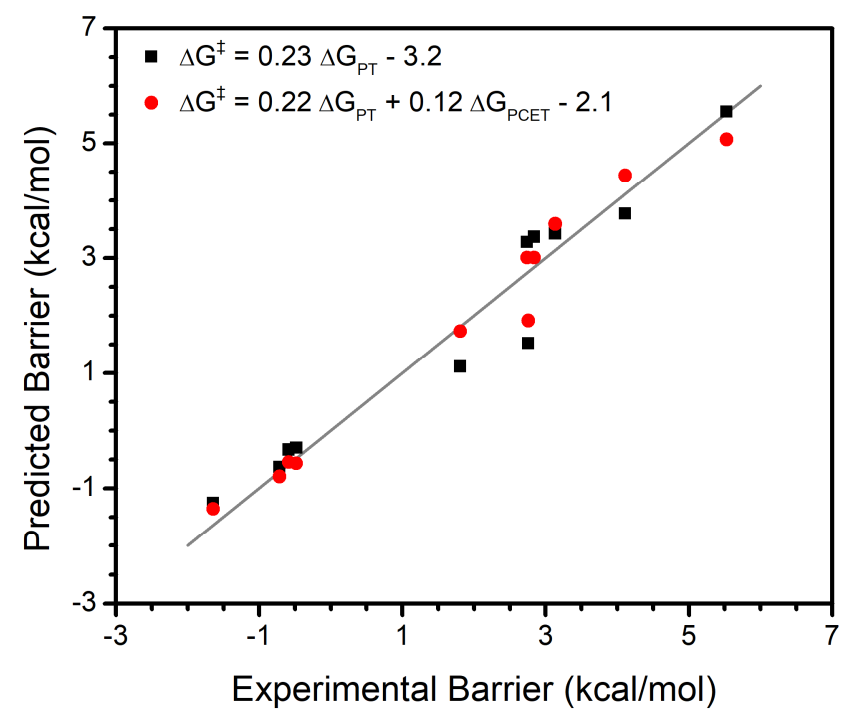

Figure 2. Regression analysis for a $\mathrm{Co}^{\mathrm{III}}$ oxo. The $\left\{\Delta \mathrm{G}_{\mathrm{PT}}\right\}$ fit is show in black with predicted values computed using the indicated formula, with $\mathrm{R}^{2}=0.94$ and $\mathrm{LOO} \mathrm{R}^{2}=0.93$. The $\left\{\Delta \mathrm{G}_{\mathrm{PT}}\right.$, $\left.\Delta \mathrm{G}_{\text {PCET }}\right\}$ fit is shown in red with predicted values computed using the indicated formula, with $\mathrm{R}^{2}=0.97$ and $\mathrm{LOO}^{2}=0.95$. The negative barriers are due to overestimation of the entropy of association. The grey line marks where the predicted barrier matches the experimentally determined barrier.

ligand 13-TMC. 47,55 The $\left\{\Delta \mathrm{GPCET}_{\mathrm{PC}} \Delta \mathrm{GPT}_{\mathrm{PT}} \Delta \mathrm{G}_{\mathrm{ET}}\right\}$ model predicts essentially no barrier for these reactions, which is not observed experimentally. This is due to a large negative calculated $\Delta \mathrm{GPCET}$ in both cases; in fact, these complexes are outliers even in the $\Delta \mathrm{G}_{\text {PCET }}$ only fit (see Regression S1). The cause of this discrepancy is not entirely clear. However, it appears to be systemic to the particular ligand scaffold rather than the identity of the metal center, which suggests this discrepancy could arise from ambiguity in the primary coordination sphere of these complexes. No structural characterization is reported for the $\mathrm{Fe}^{\mathrm{IV}}$ complex, and while a short Co-O bond is identified by EXAFS for the $\mathrm{Co}^{\mathrm{IV}}$ complex, it is difficult to conclusively determine the primary coordination sphere. Any discrepancy in coordination sphere would render our calculated parameters incorrect, potentially explaining their inability to predict the experimental reaction barriers.

The reaction barrier is overestimated for the two $\mathrm{Ru}^{\mathrm{IV}}$ oxo complexes in the set, which we suspect is due to their relatively low structural reorganization energy. ${ }^{36,43}$ We quantified structural reorganization energy for each metal oxo complex by calculating the electronic energy needed to deform the metal oxo complex from its optimized geometry to the corresponding metal hydroxide optimized geometry. By this metric, the $\mathrm{Ru}^{\mathrm{IV}}$ oxo complexes have lower structural reorganization than every other example in the set, and 6 $\mathrm{kcal} / \mathrm{mol}$ less structural reorganization energy than the properly predicted $\mathrm{Ru}^{\mathrm{VI}}$ oxo (see SI). This explanation is speculative, however, as inclusion of this parameter does not quantitatively improve the fit to the whole data set (see Regression S21). Nonetheless, the qualitative picture is consistent with the previously reported low reorganization energy of a $\mathrm{Ru}^{\mathrm{IV}}$ oxo relative to a $\mathrm{V}^{\mathrm{V}} \mathrm{oxo}^{56}$ and highlights that it is possible for parameter to affect specific cases despite not being significant globally.

Interestingly, the $\left\{\Delta \mathrm{G}_{\mathrm{PCET}}, \Delta \mathrm{G}_{\mathrm{PT}}, \Delta \mathrm{G}_{\mathrm{ET}}\right\}$ model only moderately underestimates the reaction barrier (by $2 \mathrm{kcal} / \mathrm{mol}$ ) for a terminal $\mathrm{Co}^{\mathrm{III}}$ oxo complex which has unusual trends in its reactivity with various substrates. ${ }^{15}$ Unlike most metal oxo complexes, the reactivity of this complex does not have a clear trend with $\Delta$ GPCET; its kinetics are instead dominated by $\Delta \mathrm{G}_{\mathrm{PT}}$. Therefore, its adherence to trends in $\left\{\Delta \mathrm{G}_{\mathrm{PCET}}, \Delta \mathrm{G}_{\mathrm{PT}}\right.$, $\left.\Delta \mathrm{G}_{\mathrm{ET}}\right\}$ as seen for the broad set of metal oxo complexes deserves further investigation. We regressed the experimental reaction barriers for the reactivity of this complex with several substrates against only $\Delta \mathrm{G}_{\mathrm{PT}}$ as well as against $\left\{\Delta \mathrm{G}_{\mathrm{PT}}, \Delta \mathrm{G}_{\mathrm{PCET}}\right\}$ (Figure 2). We find that the inclusion of $\Delta \mathrm{GPCET}$ significantly improves the model, increasing $\mathrm{R}^{2}$ from 0.94 to 0.97 and LOO $\mathrm{R}^{2}$ from 0.93 to 0.95 and having an F-test $p$ value of 0.02 . However, the relative weighting of the contri-

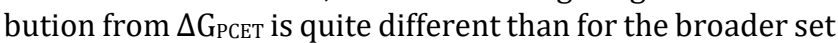
of complexes.

In the broader set we observe that $\Delta \mathrm{GPCET}$ has a larger effect on the reaction barriers than either $\Delta \mathrm{G}_{\mathrm{PT}}$ or $\Delta \mathrm{G}_{\mathrm{ET}}$, which is reflected in the larger coefficient for the $\Delta \mathrm{GPCET}$ term than for the $\Delta \mathrm{G}_{\mathrm{PT}}$ and $\Delta \mathrm{G}_{\mathrm{ET}}$ terms in the fitted equation (Figure 1). In contrast, $\Delta \mathrm{G}_{\mathrm{PT}}$ has a greater effect than $\Delta \mathrm{G}_{\mathrm{PCET}}$ on the reaction barriers for the Co ${ }^{\text {III }}$ oxo complex, again reflected in the magnitude of their coefficients (Figure 2). Furthermore, the addition of $\Delta \mathrm{G}_{\mathrm{ET}}$ significantly improves the model for broader set of metal oxo complexes (Table 1) but is insignificant for the series of substrates reacting with the $\mathrm{Co}^{\mathrm{III}}$ oxo complex ( $p$-value $>0.05$, see Regressions S28 and S29). Overall, this $\mathrm{Co}^{\mathrm{III}}$ oxo complex is not so dissimilar from the broader set of metal oxo complexes in that the same thermodynamic free energies explain the reactivity of both. However, this individual case demonstrates a different

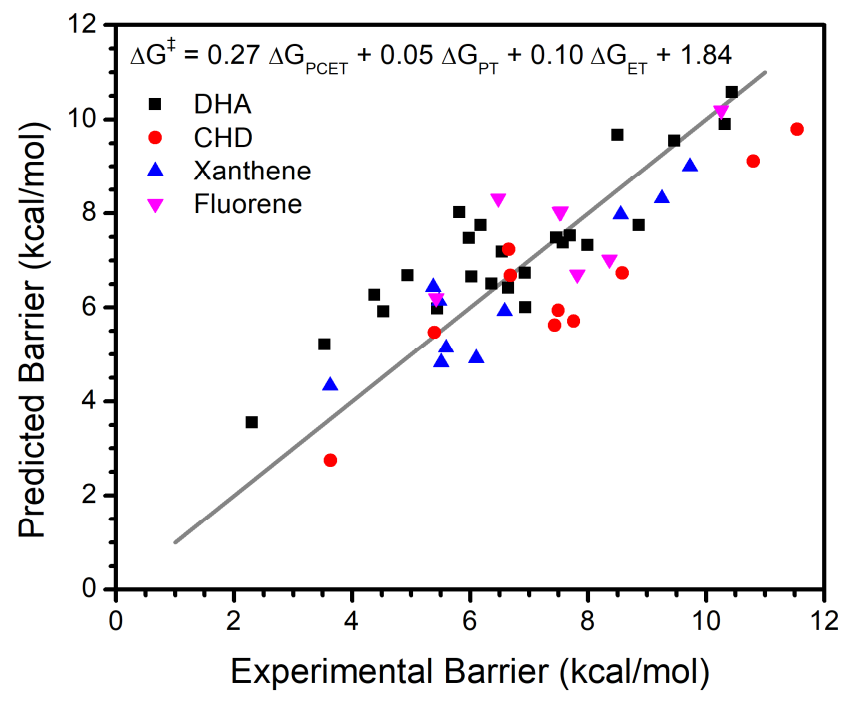

Figure 3. Regression analysis of the experimental reaction barrier to PCET mediated $\mathrm{C}-\mathrm{H}$ activation vs. $\Delta \mathrm{G}_{\mathrm{PCET}}, \Delta \mathrm{G}_{\mathrm{PT}}$, and $\Delta \mathrm{G}_{\mathrm{ET}}$ for all non-outlier metal oxo complexes reacting with DHA, CHD, xanthene, and fluorene. The grey line marks where predicted equals experimental. Predicted values are computed using the given formula. 
weighting of parameters than that observed in the broad set.

Our analysis of the $\mathrm{Co}^{\mathrm{III}}$ reactivity rests on the assumption that the coefficients of the model do not change appreciably from substrate to substrate. To test this assumption, we extended our analysis of the larger set of metal oxo complexes to include reactivity with 1,4-cyclohexadiene (CHD), fluorene, and xanthene in addition to DHA. We refit the model with reported data for the reactions between each substrate and all non-outlier metal oxo complexes (the excluded outliers are the previously discussed $\mathrm{Ru}^{\mathrm{IV}}$ and 13-TMC supported oxo complexes). As with our regressions for DHA alone, the inclusion of $\Delta \mathrm{G}_{\mathrm{PT}}$ and $\Delta \mathrm{G}_{\mathrm{ET}}$ notably improves the fit (Table 1, Figure 3). Other parameters offer comparably little improvement to the fit and do not perform well by LOO cross validation. The equation for this model is $\Delta \mathrm{G}^{*}=0.27$ $\Delta \mathrm{GPCET}+0.05 \Delta \mathrm{GPT}+0.10 \Delta \mathrm{G}_{\mathrm{ET}}+1.84$, which is satisfyingly similar to the equation of the fit to DHA data alone, supporting the assumption that the coefficients of the model are not appreciably affected by the identity of the substrate.

\section{CONCLUSION}

Overall, this thorough analysis of the reported $\mathrm{C}-\mathrm{H}$ activation reactivity of transition metal oxo complexes demonstrates that $\Delta \mathrm{G}_{\mathrm{PCET}}, \Delta \mathrm{G}_{\mathrm{PT}}$, and $\Delta \mathrm{G}_{\mathrm{ET}}$ have a statistically significant correlation with the reaction barrier. Interestingly, no other parameters examined here, including steric environment and spin-based parameters, provide a significant improvement to a $\Delta \mathrm{GPCET}_{\text {P }}$ only model. This is in contrast to previous literature reports which implicate such factors in explaining metal oxo mediated PCET. The $\left\{\Delta \mathrm{G}_{\mathrm{PCET}}, \Delta \mathrm{G}_{\mathrm{PT}}, \Delta \mathrm{G}_{\mathrm{ET}}\right\}$ model predicts all but four of the reaction barrier heights to reactivity with DHA within $2 \mathrm{kcal} / \mathrm{mol}$, and predicts most of these barrier heights within $1 \mathrm{kcal} / \mathrm{mol}$. We suspect the $\mathrm{Ru}^{\mathrm{IV}}$ oxo outliers point towards uncaptured reorganization effects. We find that the asynchronous reactivity of a $\mathrm{Co}^{\mathrm{III}}$ oxo complex is also well-predicted, although a fit to the kinetics of just this complex alone reveals changes in the relative importance of $\Delta \mathrm{G}_{\text {PCET }}$ and $\Delta \mathrm{GPT}$. The structural and electronic bases for such variation, and whether concomitant changes in selectivity can be leveraged, are exciting avenues for future research. While the relative importance of these thermodynamic parameters can vary between metal oxo complexes, and it is possible additional parameters may be determinative in some cases, this study on a broad set of metal oxo complexes suggests that thermodynamic parameters provide the greatest contribution to reaction barriers, and adds to the growing body of literature supporting the importance of off- $\Delta \mathrm{G}_{\mathrm{PCET}}$ diagonal thermodynamic contributions.

\section{METHODS}

\section{Tabulation of Experimental Kinetics}

In this study we used twenty-eight reported $k_{2}$ values of metal oxo species reacting with DHA. ${ }^{12,13,15,17,32-47}$ For each of these oxo complexes, we tabulated various descriptors (metal, valency, d-count, coordination number, etc.), experimental parameters ( $\mathrm{M}-\mathrm{O}$ bond length and vibrational frequency, BDFE, $\mathrm{p} K_{\mathrm{a}}$, etc.), and the reported kinetics for reactions with various substrates $\left(k_{2}\right.$, and, if reported, the statistical correction to this $k_{2}$, experimental $\Delta \mathrm{H}^{\ddagger}$ and $\Delta \mathrm{S}^{\ddagger}$, and the KIE) along with the conditions these data were reported in (temperature and solvent). A full tabulation is found in the SI data folder. We excluded a few metal oxo species from our analysis despite having reported kinetic data for reactivity with DHA. The reasons for these exclusions were varied: several did not have a well-defined primary coordination sphere, ${ }^{57-60}$ we were unable to calculate the reduced form of $\mathrm{Mn}^{\mathrm{III}}$ oxo complexes without deprotonation of the hydrogen-bonding ligands, ${ }^{17,20}$ one $\mathrm{V}^{\mathrm{V}}$ oxo has too much experimental uncertainty in its $k_{2}$ value, ${ }^{61}$ corrolazine complexes were too large to calculate their vibrational frequencies using our methods, ${ }^{16,62}$ we did not include third row complexes or complexes with ligand radicals, ${ }^{35,63-65}$ and in one case saturation was reported at higher concentrations of DHA. ${ }^{66}$ We also found several reports of metal oxo mediated C-H activation of substrates besides $\mathrm{DHA}^{14,37,55,67-}$ 80 and useful reviews. ${ }^{81,82}$ We believe this to be a thorough list of papers which report quantitative kinetics of metal oxo mediated $\mathrm{C}-\mathrm{H}$ activation via PCET, although some additional reports may exist.

All rate constants utilized here were reported as $k_{2}$ values with the exception of several rate constants used in the $\mathrm{Co}^{\mathrm{III}}$ oxo reactivity analysis. ${ }^{15}$ In this case, for substrates which did not have a reported $k_{2}$, the pseudo-first order rate constant $k_{\text {obs }}$ at $0.0125 \mathrm{M}$ of substrate was divided by $0.0125 \mathrm{M}$ to obtain an approximate $k_{2}$. We used all substrates with reported kinetic data in this analysis except for 1,1,3,3-tetraphenylpropene. This substrate reacts unusually slowly, which we believe to be due to large steric hindrance of the reacting $\mathrm{C}-\mathrm{H}$ bond. The remaining substrates were sterically similar enough that there is no steric effect on their kinetics (see Regression S27).

\section{Determination of Experimental Barrier Heights}

Before determining barrier heights from experimental $k_{2}$ values, we first multiplied each $k_{2}$ by any reported stochiometric and statistical adjustments so as to start from consistently unadjusted $k_{2}$ rate constants (experimental $k_{2}$ rate constants are often reported with statistical corrections to facilitate comparisons between substrates, either for the stoichiometry of the substrate's reactivity or for the number of benzylic $\mathrm{C}-\mathrm{H}$ bonds). We assume that where no adjustment is noted in a paper, none has been made. The barriers of PCET reactivity were then determined from the unadjusted experimental $k_{2}$ values by solving the Eyring equation $^{83}$ and subtracting approximate expressions for the free energy of metal oxo-substrate association:

$\Delta G_{P C E T}^{\ddagger}=R T \ln \left(\frac{k_{2} h}{n_{C H} n_{O} R T}\right)-R T\left[\ln \left(\left(\frac{2 \pi \mu R T}{h^{2}}\right)^{\frac{3}{2}} C^{\circ-1}\right)+\frac{5}{2}\right]$ (1)

where $h$ is Planck's constant, $n_{C H}$ is 2 for DHA and CHD and 1 for fluorene and xanthene, $n_{O}$ is the number of oxo ligands in the metal oxo complex, $R T$ is the thermal energy, $\mu$ is the reduced mass of the metal oxo and the substrate, and $C^{\circ}$ is $1 \mathrm{M}$. Our $n_{C H}$ adjusts for the typical stoichiometry of each substrate's oxidation (DHA and CHD tend to lose two H-atoms, fluorene and xanthene one $\mathrm{H}$-atom); we do not adjust for the number of reactive $\mathrm{H}$-atoms, as ring puckering of the substrates means that not all reactive $\mathrm{C}-\mathrm{H}$ bonds are equivalent. For instance, DHA has four benzylic $\mathrm{C}-\mathrm{H}$ bonds, with 
two lying equatorial to the central ring and two lying axial. It is unlikely that the equatorial and axial positions are equally reactive, and it is entirely possible that reactivity predominantly occurs at only one of the positions. It is therefore not necessarily true that DHA is four times as reactive as an otherwise similar substrate with only one benzylic $\mathrm{C}-\mathrm{H}$ bond.

The second and third terms in Equation 1 are an approximation for the free energy of association of the metal oxo and the substrate. ${ }^{83}$ This adjustment allows us to compare kinetic data collected at different temperatures. As $\mathrm{C}-\mathrm{H}$ bonds are poor hydrogen bond donors, we assume that the cost of association is purely entropic (or at least that enthalpic components vary minimally between different metal oxo complexes and substrates) and further assume this entropy cost is solely the loss of translational entropy. This neglects the loss of rotational entropy and the gain of low frequency metal oxo-substrate vibrational modes, but these effects will partially cancel. Regression with $\Delta \mathrm{G}_{\text {PCET }}$ and $R T$ does not fit DHA reaction barrier heights significantly better than a fit to $\Delta \mathrm{G}_{\text {PCET }}$ alone (see Regression S10), indicating that this adjustment satisfactorily accounts for the temperature dependence of the reaction barrier.

We do not take into account hydrogen bonding between the metal oxo complexes and protic solvents as we were unable to derive a suitably accurate correction. However, in the SI we demonstrate that our best attempt to do so does not change the main conclusions herein (see Table S5). ${ }^{26,84-}$ 86

\section{Calculation of Parameters}

For each of these oxo complexes we calculated the values of parameters that have been proposed to influence metal oxo mediated PCET reactivity. Specifically, the parameters investigated were \%BV steric metrics, spin density on the oxygen atom, available spin states, thermodynamic free energies $\Delta \mathrm{G}_{\mathrm{PCET}}, \Delta \mathrm{G}_{\mathrm{PT}}$, and $\Delta \mathrm{G}_{\mathrm{ET}}$, and the magnitude of the asynchronicity parameter $(|\eta|)$. Geometry optimization and frequency calculations were performed in ORCA using the def2 basis sets of Weigend and Ahlrichs and the O3LYP functional. ${ }^{87-92}$ For the wider set of metal oxo complexes, all transition metals were given the def2-TZVPP basis set, all metal-bonded atoms and the transferring hydrogen atom the def2-TZVP basis set, and the remaining atoms the def2SV(P) basis set. Substrates were calculated entirely with the def2-TZVP basis set. For calculations regarding the $\mathrm{Co}^{\mathrm{III}}$ oxo and various substrates, $\mathrm{Co}, \mathrm{N}, \mathrm{O}$, the carbene carbons of the ligand, and the carbon undergoing $\mathrm{C}-\mathrm{H}$ activation was given def2-TZVPP; all other atoms were given def2-SVP. For both sets of calculations solvent effects were included as a polarizable continuum (CPCM with the dielectric constant of acetonitrile for the broader set of metal oxo complexes; COSMO with the dielectric constant of THF for the $\mathrm{Co}^{\text {III }}$ oxo with substrates). This is primarily to mitigate the effect of self-interaction error; ${ }^{93}$ we assume that the solvent dielectric has little effect on the rate of PCET, as reported solvent effects on similar reactions are typically limited to hydrogen bonding. ${ }^{26,86,94}$ The def2 ECP was used for ruthenium. ${ }^{95}$ The resolution of identity approximation was used for coulomb integrals and the chain of spheres approximation for exchange integrals (with def2/J as the auxiliary basis). No change was made to ORCA's default grid settings. Free energies were derived from the electronic energies and vibrational calculations using the quasi-harmonic oscillator formulation of Grimme and coworkers. ${ }^{96}$

Unfortunately, several of our optimized structures have small imaginary frequencies (See SI), which we believe is due to numerical noise of CPCM solvation. Occasionally these frequencies lie below $-100 \mathrm{~cm}^{-1}$ but in each of these cases the mode is isolated to a soft dihedral motion, e.g. methyl rotation on an acetonitrile ligand. We used the absolute value of these frequencies when calculating the thermodynamic enthalpy and entropy values, believing that to be a better approximation for these modes than either nonexistence or a frequency of $0 \mathrm{~cm}^{-1}$. We were unable to reoptimize these structures to remove the imaginary frequencies.

In many cases, the correct ground state multiplicity of a species was not immediately clear. In such cases we confirmed our initial assignment by running ten geometry optimization cycles on alternate spin states and confirming these alternate assignments were several kcal/mol uphill of the assigned spin state. In a few cases were the energy was within $5 \mathrm{kcal} / \mathrm{mol}$ and the optimization was not close to convergence, we fully optimized the alternate spin state. Whenever two spin states had nearly the same energy, we chose the higher spin state as the ground state due to the typically higher entropy of high spin states.

To quantify the steric environment around each metal oxo center or substrate reactive $\mathrm{C}-\mathrm{H}$ bond, we calculated percent buried volume $(\% \mathrm{BV})$ steric metrics using the online SambVCA web application. ${ }^{48}$ We centered the calculation on the oxygen atom (for oxos) or the transferring hydrogen (for substrates), defined the negative z-axis as going through the metal center (for oxos) or the reacting carbon center (for substrates), and defined the xz plane as containing another atom bonded to the metal or carbon (the first such atom in the .xyz file). We had the center oxygen or hydrogen atom deleted from the calculation, included hydrogen atoms in the calculation, and left all other settings to their default value (using Bondi radii scaled by 1.17 , a sphere radius of 3.5 Angstroms, and a mesh setting of 0.10 Angstroms). The application returns a total percent buried volume, as well as that for individual quadrants of the sphere. For metal oxo complexes, we used the total percent buried volume (\%BV Tot) and the standard deviation of these four quadrants (\%BV Dev) in our regressions in order to capture both overall steric bulk and how evenly distributed this bulk is around the metal oxo moiety. For substrates, we solely used \%BV Tot. See the SI for a further discussion of steric parameters and their effect on reaction barrier heights.

To evaluate the effect of spin and spin state on reactivity, we used two parameters that have been discussed in the literature: spin density on the oxo ligand and the energy to excite to a higher spin state. ${ }^{8,10}$ Atomic spin populations were determined via IBO analysis using the freely available IBO Viewer software. ${ }^{49,50}$ We recorded the spin density on the metal and on oxygen for each metal oxo complex as well as how much spin both atoms gain upon PCET reduction; we also tabulated similar values for the IBO charges. In the regression analysis we solely used the spin density on the oxo 
ligand. The "Spin Excitation Energy" is the vertical energy from the ground spin state of the initial oxo complex to the lowest lying excited spin state that is within one spin multiplicity of the resulting metal hydroxide ground spin state. If the ground spin state is already one spin multiplicity greater or lower than the product hydroxide spin state, then the spin excitation energy is taken to be zero. For instance, in the case of a triplet $\mathrm{Fe}^{\mathrm{IV}}$ oxo reacting to give a sextet $\mathrm{Fe}^{\mathrm{III}}$ hydroxide the spin excitation energy is the energy of the quintet $\mathrm{Fe}^{\mathrm{IV}}$ oxo relative to the triplet $\mathrm{Fe}^{\mathrm{IV}}$ oxo at the ground state optimized geometry. This is the scenario for most $\mathrm{Fe}^{\mathrm{IV}}$ oxos in the data set. But in the case of the two non-heme $\mathrm{Fe}^{\mathrm{IV}}$ quintet oxos, ${ }^{12,13}$ the spin excitation energy is zero because the ground spin state is already within one spin multiplicity of the sextet hydroxide product. Essentially, the spin excitation energy is the energy needed to reach a spin surface on which reduction to the metal hydroxide's ground spin state is spin allowed. While this simple metric ignores the nuances of two state reactivity theory (such as the spin inversion probability) it is relatively simple to compute and has precedent as a quantitative measure of PCET reactivity. ${ }^{10,34}$

For each metal oxo-substrate combination assessed here, we tabulated the free energies of proton coupled electron

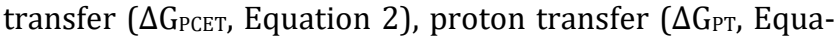
tion 3$)$, electron transfer ( $\Delta \mathrm{GET}_{\mathrm{ET}}$, Equation 4$)$, and the asynchronicity as defined by Srnec and coworkers $(\eta$, Equation 5):21

$$
\begin{gathered}
\Delta G_{P C E T}=G_{M-O H}+G_{C \cdot}-G_{M=O}-G_{C-H}(2) \\
\Delta G_{P T}=G_{M-O H^{+}}+G_{C:^{-}}-G_{M=O}-G_{C-H}(3) \\
\Delta G_{E T}=G_{M-O^{-}}+G_{C-H^{+}}-G_{M=O}-G_{C-H}(4) \\
\eta=G_{M-O H^{+}}+G_{C:^{-}}-G_{M-O^{-}}-G_{C-H^{+}} /_{\sqrt{2}}(5)
\end{gathered}
$$

where $G_{M=O}$ is the calculated free energy of the oxo species, $G_{C-H}$ is the calculated free energy of the substrate, and all other free energies are defined analogously. We also tabulated the absolute value of the asynchronicity $(|\eta|)$, the average of $\Delta \mathrm{G}_{\mathrm{PT}}$ and $\Delta \mathrm{G}_{\mathrm{ET}}\left(\Delta \mathrm{G}_{\mathrm{CT}}\right.$ Average), and the analogous electronic energies (same notation, with $\mathrm{G}$ replaced with $\mathrm{E}$ ).

\section{Statistical Analysis}

All statistical analysis was performed in Python using the Numpy, Scipy, Pandas, Sklearn, and Matplotlib packages. ${ }^{97-}$ 101 A script ran a prescribed set of regression models and reported statistics on each model. All regressions were performed with ordinary least squares. Prior to fitting any regression, we separated the data into a test set and a training set of metal oxo species. While we show both test and training sets for each regression in the SI, we initially did not plot the test set or calculate statistics with it. We solely used the training set in the earlier stages of our analysis, where we determined which parameters improved a fit to $\Delta$ G PCET only and which did not. We then examined if the good fits to the training set extrapolated well to the test set. We had to make a few changes to the initial division of the training and test sets, however. Initially, the $\mathrm{Co}^{\mathrm{IV}}$ oxo was included in the training set, ${ }^{47}$ but that was interfering with the fit to $\Delta \mathrm{G}_{\text {PCET }}$. We moved it to the test set, and to provide insight into this poor fit we calculated the Fe $\mathrm{FV}^{\mathrm{IV}}$ oxo complex of 13-TMC and added it to the test set. ${ }^{55}$ We also saw, visually, that the inclusion of a $\mathrm{Ru}^{\mathrm{IV}}$ oxo in the training set (the other $\mathrm{Ru}^{\mathrm{IV}}$ oxo example was always in the test set) was interfering with the addition of other parameters and moved all $\mathrm{Ru}$ oxo complexes to the test set. $36,41,43$

The simplest metrics reported from these models are the mean square error (MSE) and the goodness of fit $\mathrm{R}^{2}{ }^{251-54}$ These both give an indication of how well a model fits the available data but are prone to overfitting; more complicated models can only improve these metrics, regardless of whether or not the model is actually better.

We also evaluated each model with cross validation (CV) metrics, which can become worse upon overfitting. In K-fold cross validation, the training data is further subdivided into $\mathrm{K}$ subsets, and each subset is predicted by the K-1 remaining subsets. ${ }^{52,54}$ When $\mathrm{K}$ is the number of data points, i.e. each data point being predicted by the rest of the data points, this is known as leave-one-out (LOO) cross validation. These predicted data points can be used to calculate the MSE and $\mathrm{R}^{2}$ as above. The MSE from LOO cross validation is an approximately unbiased estimate of the expected error of a test set; however, it has high variability from training set to training set because each prediction uses nearly every point in a given training set. By repeatedly subdividing into larger groups and averaging the resultant $\mathrm{K}$ fold MSEs, one obtains a pessimistic but less variable estimate of the expected test error. As we see similar trends for both LOO and 5-fold CV, we only report LOO R ${ }^{2}$ in the main text but show all metrics in the SI.

Another way to determine the significance of the model is to use a statistical F-test. ${ }^{51,53}$ This allows one to compare an unrestricted model with a more restricted one (fewer parameters used as regressors, or no parameters regressed, or restrictions placed on the relationship between coefficients, etc.). In the language of hypothesis testing, the null hypothesis is that the unrestricted model offers no improvement on the restricted model and the alternate hypothesis is that there is an improvement. When both models are fit to the data, the unrestricted model will have less total squared error than the restricted model. Assuming said error of each data point is normally distributed (or that there is enough data such that the error is approximately normally distributed), that the average error is zero, and that the model is properly formulated, it is possible to determine the probability that this reduction in total squared error is spurious. This probability is known as the p-value. The test relies on a well-defined number of degrees of freedom in both the restricted and unrestricted model to draw out what the statistical distribution of total squared error ought to be.

For regressions on multiple substrates at once, the unequal weighting of different metal oxo complexes (depending on how many substrates are reported for them) renders these statistical metrics unreliable. ${ }^{54} \mathrm{We}$ ameliorate this issue for LOO cross validation by leaving out all reaction barriers for a given metal oxo complex together rather than one at a time. That is, we leave one metal oxo complex out and predict its reaction barrier heights based on all other metal oxos' reaction barrier heights rather than leave one reaction barrier height out and predict this barrier based off all other 
barriers. We accordingly only report LOO CV metrics for this set of regressions.

\section{AUTHOR INFORMATION}

\section{Corresponding Author}

*jsanderson@uchicago.edu

Notes

The authors declare no competing financial interests.

\section{ACKNOWLEDGMENT}

This work was funded by the National Institutes of Health (R35 GM133470), the National Science Foundation (1654144), and the University of Chicago. J.E.S. thanks the Department of Defense for a National Defense Science and Engineering Graduate Fellowship (00003765) and J.S.A. thanks the Sloan Foundation for a Research Fellowship (FG-2019-11497). Computations were generously supported by the UChicago Research Computing Center. We also acknowledge useful discussions with Dr. Daniel Bím.

\section{REFERENCES}

(1) Milan, M.; Salamone, M.; Costas, M.; Bietti, M. The Quest for Selectivity in Hydrogen Atom Transfer Based Aliphatic C-H Bond Oxygenation. Acc. Chem. Res. 2018, 51 (9), 1984-1995.

(2) Gray, H. B.; Winkler, J. R. Living with Oxygen. Acc. Chem. Res. 2018, 51 (8), 1850-1857.

(3) Yin, G. Active transition metal oxo and hydroxo moieties in nature's redox, enzymes and their synthetic models: Structure and reactivity relationships. Coord. Chem. Rev. 2010, 254 (15), 1826-1842.

(4) Lai, W.; Li, C.; Chen, H.; Shaik, S. Hydrogen-Abstraction Reactivity Patterns from A to Y: The Valence Bond Way. Angew. Chem. Int. Ed. 2012, 51 (23), 5556-5578.

(5) Mayer, J. M. Simple Marcus-Theory-Type Model for HydrogenAtom Transfer/Proton-Coupled Electron Transfer. J. Phys. Chem. Lett. 2011, 2 (12), 1481-1489.

(6) Mayer, J. M. Understanding Hydrogen Atom Transfer: From Bond Strengths to Marcus Theory. Acc. Chem. Res. 2011, 44 (1), 36-46.

(7) Dhar, D.; Yee, G. M.; Spaeth, A. D.; Boyce, D. W.; Zhang, H.; Dereli, B.; Cramer, C. J.; Tolman, W. B. Perturbing the Copper(III)Hydroxide Unit through Ligand Structural Variation. J. Am. Chem. Soc. 2016, 138 (1), 356-368.

(8) Dietl, N.; Schlangen, M.; Schwarz, H. Thermal Hydrogen-Atom Transfer from Methane: The Role of Radicals and Spin States in Oxo-Cluster Chemistry. Angew. Chem. Int. Ed. 2012, 51 (23), 5544-5555. https://doi.org/10.1002/anie.201108363.

(9) Dhuri, S. N.; Seo, M. S.; Lee, Y.-M.; Hirao, H.; Wang, Y.; Nam, W.; Shaik, S. Experiment and Theory Reveal the Fundamental Difference between Two-State and Single-State Reactivity Patterns in Nonheme FeIV=0 versus RuIV=0 Oxidants. Angew. Chem. Int. Ed. 2008, 47 (18), 3356-3359.

(10) Cho, K.-B.; Kim, E. J.; Seo, M. S.; Shaik, S.; Nam, W. Correlating DFT-Calculated Energy Barriers to Experiments in Nonheme Octahedral FeIVO Species. Chem. Eur. J. 2012, 18 (33), 1044410453.

(11) Usharani, D.; Janardanan, D.; Li, C.; Shaik, S. A Theory for Bioinorganic Chemical Reactivity of Oxometal Complexes and Analogous Oxidants: The Exchange and Orbital-Selection Rules. Acc. Chem. Res. 2013, 46 (2), 471-482.

(12) England, J.; Guo, Y.; Van Heuvelen, K. M.; Cranswick, M. A. Rohde, G. T.; Bominaar, E. L.; Münck, E.; Que, L. A More Reactive Trigonal-Bipyramidal High-Spin Oxoiron(IV) Complex with a cis-Labile Site. J. Am. Chem. Soc. 2011, 133 (31), 1188011883.

(13) England, J.; Martinho, M.; Farquhar, E. R.; Frisch, J. R.; Bominaar, E. L.; Münck, E.; Que, L. A Synthetic High-Spin Oxoiron(IV) Complex: Generation, Spectroscopic
Characterization, and Reactivity. Angew. Chem. Int. Ed. 2009, 48 (20), 3622-3626.

(14) Bigi, J. P.; Harman, W. H.; Lassalle-Kaiser, B.; Robles, D. M.; Stich, T. A.; Yano, J.; Britt, R. D.; Chang, C. J. A High-Spin Iron(IV)-Oxo Complex Supported by a Trigonal Nonheme Pyrrolide Platform. J. Am. Chem. Soc. 2012, 134 (3), 15361542.

(15) Goetz, M. K.; Anderson, J. S. Experimental Evidence for pKaDriven Asynchronicity in $\mathrm{C}-\mathrm{H}$ Activation by a Terminal Co(III)-Oxo Complex. J. Am. Chem. Soc. 2019, 141 (9), 40514062.

(16) Lansky, D. E.; Goldberg, D. P. Hydrogen Atom Abstraction by a High-Valent Manganese(V)-Oxo Corrolazine. Inorg. Chem. 2006, 45 (13), 5119-5125.

(17) Parsell, T. H.; Yang, M.-Y.; Borovik, A. S. C-H Bond Cleavage with Reductants: Re-Investigating the Reactivity of Monomeric MnIII/IV-Oxo Complexes and the Role of Oxo Ligand Basicity. J. Am. Chem. Soc. 2009, 131 (8), 2762-2763.

(18) Yosca, T. H.; Rittle, J.; Krest, C. M.; Onderko, E. L.; Silakov, A.; Calixto, J. C.; Behan, R. K.; Green, M. T. Iron(IV)hydroxide pKa and the Role of Thiolate Ligation in $\mathrm{C}-\mathrm{H}$ Bond Activation by Cytochrome P450. Science 2013, 342 (6160), 825-829.

(19) Baglia, R. A.; Krest, C. M.; Yang, T.; Leeladee, P.; Goldberg, D. P. High-Valent Manganese-Oxo Valence Tautomers and the Influence of Lewis/Brönsted Acids on C-H Bond Cleavage. Inorg. Chem. 2016, 55 (20), 10800-10809.

(20) Barman, S. K.; Jones, J. R.; Sun, C.; Hill, E. A.; Ziller, J. W.; Borovik, A. S. Regulating the Basicity of Metal-Oxido Complexes with a Single Hydrogen Bond and Its Effect on $\mathrm{C}-\mathrm{H}$ Bond Cleavage. J. Am. Chem. Soc. 2019, 141 (28), 11142-11150.

(21) Bím, D.; Maldonado-Domínguez, M.; Rulíšek, L.; Srnec, M. Beyond the classical thermodynamic contributions to hydrogen atom abstraction reactivity. Proc. Natl. Acad. Sci. U.S.A. 2018 115 (44), E10287-E10294.

(22) Bím, D.; Maldonado-Domínguez, M.; Fuč́́k, R.; Srnec, M. Dissecting the Temperature Dependence of Electron-Proton Transfer Reactivity. J. Phys. Chem. C 2019, 123 (35), 2142221428.

(23) Maldonado-Domínguez, M.; Bím, D.; Fučík, R.; Čurík, R.; Srnec, M. Reactive mode composition factor analysis of transition states: the case of coupled electron-proton transfers. Phys. Chem. Chem. Phys. 2019, 21 (45), 24912-24918.

(24) Maldonado-Domínguez, M.; Srnec, M. Understanding and Predicting Post H-Atom Abstraction Selectivity through Reactive Mode Composition Factor Analysis. J. Am. Chem. Soc. 2020, 142 (8), 3947-3958.

(25) Saouma, C. T.; Mayer, J. M. Do spin state and spin density affect hydrogen atom transfer reactivity? Chem. Sci. 2013, 5 (1), 2131.

(26) Warren, J. J.; Mayer, J. M. Predicting organic hydrogen atom transfer rate constants using the Marcus cross relation. Proc. Natl. Acad. Sci. U.S.A. 2010, 107 (12), 5282-5287.

(27) Reid, J. P.; Sigman, M. S. Holistic prediction of enantioselectivity in asymmetric catalysis. Nature 2019, 571 (7765), 343348.

(28) Maldonado, A. G.; Rothenberg, G. Predictive modeling in homogeneous catalysis: a tutorial. Chem. Soc. Rev. 2010, 39 (6), 1891-1902.

(29) Jorner, K.; Brinck, T.; Norrby, P.-O.; Buttar, D. Machine Learning Meets Mechanistic Modelling for Accurate Prediction of Experimental Activation Energies. 2020 https://doi.org/10.26434/chemrxiv.12758498.v1.

(30) B. Santiago, C.; Guo, J.-Y.; S. Sigman, M. Predictive and mechanistic multivariate linear regression models for reaction development. Chem. Sci. 2018, 9 (9), 2398-2412.

(31) P. Roberts, B.; J. Steel, A. An extended form of the Evans-Polanyi equation: a simple empirical relationship for the prediction of activation energies for hydrogen-atom transfer reactions. J. Chem. Soc., Perkin Trans. 2 1994, 0 (10), 2155-2162.

(32) Sook Seo, M.; Hee Kim, N.; Cho, K.-B.; Eun So, J.; Kyung Park, S.; Clémancey, M.; Garcia-Serres, R.; Latour, J.-M.; Shaik, S.; Nam, W. A mononuclear nonheme iron(iv)-oxo complex which is 
more reactive than cytochrome $\mathrm{P} 450$ model compound I. Chem. Sci. 2011, 2 (6), 1039-1045.

(33) Kundu, S.; Thompson, J. V. K.; Shen, L. Q.; Mills, M. R.; Bominaar, E. L.; Ryabov, A. D.; Collins, T. J. Activation Parameters as Mechanistic Probes in the TAML Iron(V)-Oxo Oxidations of Hydrocarbons. Chem. Eur. J. 2015, 21 (4), 1803-1810.

(34) Sastri, C. V.; Lee, J.; Oh, K.; Lee, Y. J.; Lee, J.; Jackson, T. A.; Ray, K.; Hirao, H.; Shin, W.; Halfen, J. A.; Kim, J.; Que, L.; Shaik, S.; Nam, W. Axial ligand tuning of a nonheme iron(IV)-oxo unit for hydrogen atom abstraction. Proc. Natl. Acad. Sci. U.S.A. 2007, 104 (49), 19181-19186.

(35) Fertinger, C.; Hessenauer-Ilicheva, N.; Franke, A.; van Eldik, R. Direct Comparison of the Reactivity of Model Complexes for Compounds 0 , I, and II in Oxygenation, Hydrogen-Abstraction, and Hydride-Transfer Processes. Chem. Eur. J. 2009, 15 (48), 13435-13440. https://doi.org/10.1002/chem.200901804.

(36) Kojima, T.; Nakayama, K.; Ikemura, K.; Ogura, T.; Fukuzumi, S. Formation of a Ruthenium(IV)-Oxo Complex by ElectronTransfer Oxidation of a Coordinatively Saturated Ruthenium(II) Complex and Detection of Oxygen-Rebound Intermediates in $\mathrm{C}-\mathrm{H}$ Bond Oxygenation. J. Am. Chem. Soc. 2011, 133 (30), 11692-11700.

(37) Jeong, Y. J.; Kang, Y.; Han, A.-R.; Lee, Y.-M.; Kotani, H.; Fukuzumi, S.; Nam, W. Hydrogen Atom Abstraction and Hydride Transfer Reactions by Iron(IV)-Oxo Porphyrins. Angew. Chem. Int. Ed. 2008, 47 (38), 7321-7324.

(38) Gardner, K. A.; Kuehnert, L. L.; Mayer, J. M. Hydrogen Atom Abstraction by Permanganate: Oxidations of Arylalkanes in Organic Solvents. Inorg. Chem. 1997, 36 (10), 2069-2078.

(39) Arunkumar, C.; Lee, Y.-M.; Lee, J. Y.; Fukuzumi, S.; Nam, W. Hydrogen-Atom Abstraction Reactions by Manganese(V)- and Manganese(IV)-Oxo Porphyrin Complexes in Aqueous Solution. Chem. Eur. J. 2009, 15 (43), 11482-11489.

(40) Cho, K.-B.; Kang, H.; Woo, J.; Park, Y. J.; Seo, M. S.; Cho, J.; Nam, W. Mechanistic Insights into the $\mathrm{C}-\mathrm{H}$ Bond Activation of Hydrocarbons by Chromium(IV) Oxo and Chromium(III) Superoxo Complexes. Inorg. Chem. 2014, 53 (1), 645-652.

(41) Dhuri, S. N.; Lee, Y.-M.; Seo, M. S.; Cho, J.; Narulkar, D. D.; Fukuzumi, S.; Nam, W. Mechanistic insights into the reactions of hydride transfer versus hydrogen atom transfer by a trans-dioxoruthenium(VI) complex. Dalton Trans. 2015, 44 (16), 76347642 .

(42) Wang, D.; Ray, K.; J. Collins, M.; R. Farquhar, E.; R. Frisch, J.; Gómez, L.; A. Jackson, T.; Kerscher, M.; Waleska, A.; Comba, P.; Costas, M.; Que, L. Nonheme oxoiron(iv) complexes of pentadentate N5 ligands : spectroscopy, electrochemistry, and oxidative reactivity. Chem. Sci. 2013, 4 (1), 282-291.

(43) Bryant, J. R.; Mayer, J. M. Oxidation of $\mathrm{C}-\mathrm{H}$ Bonds by [(bpy)2(py)RuIVo]2+ Occurs by Hydrogen Atom Abstraction. J. Am. Chem. Soc. 2003, 125 (34), 10351-10361.

(44) Yin, G.; Danby, A. M.; Kitko, D.; Carter, J. D.; Scheper, W. M.; Busch, D. H. Oxidative Reactivity Difference among the Metal Oxo and Metal Hydroxo Moieties: pH Dependent Hydrogen Abstraction by a Manganese(IV) Complex Having Two Hydroxide Ligands. J. Am. Chem. Soc. 2008, 130 (48), 1624516253.

(45) Hong, S.; So, H.; Yoon, H.; Cho, K.-B.; Lee, Y.-M.; Fukuzumi, S.; Nam, W. Reactivity comparison of high-valent iron(iv)-oxo complexes bearing $\mathrm{N}$-tetramethylated cyclam ligands with different ring size. Dalton Trans. 2013, 42 (22), 7842-7845.

(46) F. Leto, D.; Ingram, R.; W. Day, V.; A. Jackson, T. Spectroscopic properties and reactivity of a mononuclear oxomanganese(iv) complex. ChemComm. 2013, 49 (47), 5378-5380.

(47) Wang, B.; Lee, Y.-M.; Tcho, W.-Y.; Tussupbayev, S.; Kim, S.-T.; Kim, Y.; Seo, M. S.; Cho, K.-B.; Dede, Y.; Keegan, B. C.; Ogura, T.; Kim, S. H.; Ohta, T.; Baik, M.-H.; Ray, K.; Shearer, J.; Nam, W. Synthesis and reactivity of a mononuclear non-haem cobalt(IV)-oxo complex. Nat. Commun. 2017, 8, 14839.

(48) Falivene, L.; Cao, Z.; Petta, A.; Serra, L.; Poater, A.; Oliva, R.; Scarano, V.; Cavallo, L. Towards the online computer-aided design of catalytic pockets. Nat. Chem. 2019, 11 (10), 872879.
(49) Knizia, G. Intrinsic Atomic Orbitals: An Unbiased Bridge between Quantum Theory and Chemical Concepts. J. Chem. Theory Comput. 2013, 9 (11), 4834-4843.

(50) Knizia, G.; Klein, J. E. M. N. Electron Flow in Reaction Mechanisms-Revealed from First Principles. Angew. Chem. Int. Ed. 2015, 54 (18), 5518-5522.

(51) Freedman, D. Statistical models: theory and practice; Cambridge University Press: Cambridge, 2005.

(52) Hastie, T.; Friedman, J.; Tisbshirani, R. The Elements of statistical learning: data mining, inference, and prediction; Springer: New York, 2018.

(53) R. Carter Hill; William E. Griffiths; Guay C. Lim. Principles of econometrics, 4th ed.; Wiley: Hoboken, NJ, 2011.

(54) Buitinck, L.; Louppe, G.; Blondel, M.; Pedregosa, F.; Mueller, A.; Grisel, O.; Niculae, V.; Prettenhofer, P.; Gramfort, A.; Grobler, J.; Layton, R.; Vanderplas, J.; Joly, A.; Holt, B.; Varoquaux, G. API design for machine learning software: experiences from the scikit-learn project. arXiv:1309.0238 [cs] 2013.

(55) Hong, S.; Lee, Y.-M.; Cho, K.-B.; Sundaravel, K.; Cho, J.; Kim, M. J.; Shin, W.; Nam, W. Ligand Topology Effect on the Reactivity of a Mononuclear Nonheme Iron(IV)-Oxo Complex in Oxygenation Reactions. J. Am. Chem. Soc. 2011, 133 (31), 1187611879.

(56) Waidmann, C. R.; Zhou, X.; Tsai, E. A.; Kaminsky, W.; Hrovat, D. A.; Borden, W. T.; Mayer, J. M. Slow Hydrogen Atom Transfer Reactions of Oxo- and Hydroxo-Vanadium Compounds: The Importance of Intrinsic Barriers. J. Am. Chem. Soc. 2009, 131 (13), 4729-4743.

(57) Company, A.; Prat, I.; Frisch, J. R.; Mas-Ballesté, D. R.; Güell, M.; Juhász, G.; Ribas, X.; Münck, D. E.; Luis, J. M.; Que, L.; Costas, M. Modeling the cis-Oxo-Labile Binding Site Motif of Non-Heme Iron Oxygenases: Water Exchange and Oxidation Reactivity of a Non-Heme Iron(IV)-Oxo Compound Bearing a Tripodal Tetradentate Ligand. Chem. Eur. J. 2011, 17 (5), 1622-1634.

(58) Fiedler, A. T.; Que, L. Reactivities of Fe(IV) Complexes with Oxo, Hydroxo, and Alkylperoxo Ligands: An Experimental and Computational Study. Inorg. Chem. 2009, 48 (23), 1103811047.

(59) Planas, O.; Clémancey, M.; Latour, J.-M.; Company, A.; Costas, M. Structural modeling of iron halogenases: synthesis and reactivity of halide-iron(IV)-oxo compounds. ChemComm. 2014, 50 (74), 10887-10890.

(60) Sawant, S. C.; Wu, X.; Cho, J.; Cho, K.-B.; Kim, S. H.; Seo, M. S.; Lee, Y.-M.; Kubo, M.; Ogura, T.; Shaik, S.; Nam, W. Water as an Oxygen Source: Synthesis, Characterization, and Reactivity Studies of a Mononuclear Nonheme Manganese(IV) Oxo Complex. Angew. Chem. Int. Ed. 2010, 49 (44), 8190-8194.

(61) Waidmann, C. R.; Zhou, X.; Tsai, E. A.; Kaminsky, W.; Hrovat, D. A.; Borden, W. T.; Mayer, J. M. Slow Hydrogen Atom Transfer Reactions of Oxo- and Hydroxo-Vanadium Compounds: The Importance of Intrinsic Barriers. J. Am. Chem. Soc. 2009, 131 (13), 4729-4743.

(62) Prokop, K. A.; de Visser, S. P.; Goldberg, D. P. Unprecedented Rate Enhancements of Hydrogen-Atom Transfer to a Manganese(V)-Oxo Corrolazine Complex. Angew. Chem. Int. Ed. 2010, 49 (30), 5091-5095.

(63) Liu, Y.; Ng, S.-M.; Lam, W. W. Y.; Yiu, S.-M.; Lau, T.-C. A Highly Reactive Seven-Coordinate Osmium(V) Oxo Complex: $[\mathrm{OsV}(0)(\mathrm{qpy})(\mathrm{pic}) \mathrm{Cl}] 2+$. Angew. Chem. 2016, 128 (1), 296299.

(64) Cho, K.; Leeladee, P.; McGown, A. J.; DeBeer, S.; Goldberg, D. P. A High-Valent Iron-Oxo Corrolazine Activates $\mathrm{C}-\mathrm{H}$ Bonds via Hydrogen-Atom Transfer. J. Am. Chem. Soc. 2012, 134 (17), 7392-7399.

(65) T. Zaragoza, J. P.; A. Siegler, M.; P. Goldberg, D. Rhenium(v)oxo corrolazines: isolating redox-active ligand reactivity. ChemComm. 2016, 52 (1), 167-170.

(66) Garcia-Bosch, I.; Company, A.; Cady, C. W.; Styring, S.; Browne, W. R.; Ribas, X.; Costas, M. Evidence for a Precursor Complex in $\mathrm{C}-\mathrm{H}$ Hydrogen Atom Transfer Reactions Mediated by a Manganese(IV) Oxo Complex. Angew. Chem. Int. Ed. 2011, 50 (25), 5648-5653. 
(67) Wu, X.; Seo, M. S.; Davis, K. M.; Lee, Y.-M.; Chen, J.; Cho, K.-B.; Pushkar, Y. N.; Nam, W. A Highly Reactive Mononuclear NonHeme Manganese(IV)-Oxo Complex That Can Activate the Strong C-H Bonds of Alkanes. J. Am. Chem. Soc. 2011, 133 (50), 20088-20091.

(68) Chen, J.; Lee, Y.-M.; Davis, K. M.; Wu, X.; Seo, M. S.; Cho, K.-B.; Yoon, H.; Park, Y. J.; Fukuzumi, S.; Pushkar, Y. N.; Nam, W. A Mononuclear Non-Heme Manganese(IV)-Oxo Complex Binding Redox-Inactive Metal Ions. J. Am. Chem. Soc. 2013, 135 (17), 6388-6391.

(69) England, J.; O. Bigelow, J.; Heuvelen, K. M. V.; R. Farquhar, E.; Martinho, M.; K. Meier, K.; R. Frisch, J.; Münck, E.; Que, L. An ultra-stable oxoiron(iv) complex and its blue conjugate base. Chem. Sci. 2014, 5 (3), 1204-1215.

(70) Cook, G. K.; Mayer, J. M. C-H Bond Activation by Metal Oxo Species: Chromyl Chloride Oxidations of Cyclooctane, Isobutane, and Toluene. J. Am. Chem. Soc. 1995, 117 (27), 7139-7156.

(71) Dhuri, S. N.; Seo, M. S.; Lee, Y.-M.; Hirao, H.; Wang, Y.; Nam, W.; Shaik, S. Experiment and Theory Reveal the Fundamental Difference between Two-State and Single-State Reactivity Patterns in Nonheme FeIV-O versus RuIV-O Oxidants. Angew. Chem. Int. Ed. 2008, 47 (18), 3356-3359.

(72) Wilson, S. A.; Chen, J.; Hong, S.; Lee, Y.-M.; Clémancey, M.; Garcia-Serres, R.; Nomura, T.; Ogura, T.; Latour, J.-M.; Hedman, B.; Hodgson, K. O.; Nam, W.; Solomon, E. I. $[\mathrm{FeIV}=0(\mathrm{TBC})(\mathrm{CH} 3 \mathrm{CN})] 2+$ : Comparative Reactivity of Iron(IV)-Oxo Species with Constrained Equatorial Cyclam Ligation. J. Am. Chem. Soc. 2012, 134 (28), 11791-11806.

(73) Nam, W.; Park, S.-E.; Lim, I. K.; Lim, M. H.; Hong, J.; Kim, J. First Direct Evidence for Stereospecific Olefin Epoxidation and $\mathrm{Al}$ kane Hydroxylation by an Oxoiron(IV) Porphyrin Complex. J. Am. Chem. Soc. 2003, 125 (48), 14674-14675.

(74) Ghosh, M.; Singh, K. K.; Panda, C.; Weitz, A.; Hendrich, M. P.; Collins, T. J.; Dhar, B. B.; Sen Gupta, S. Formation of a Room Temperature Stable FeV(O) Complex: Reactivity Toward Unactivated C-H Bonds. J. Am. Chem. Soc. 2014, 136 (27), 95249527.

(75) Biswas, A. N.; Puri, M.; Meier, K. K.; Oloo, W. N.; Rohde, G. T.; Bominaar, E. L.; Münck, E.; Que, L. Modeling TauD-J: A HighSpin Nonheme Oxoiron(IV) Complex with High Reactivity toward C-H Bonds. J. Am. Chem. Soc. 2015, 137 (7), 2428-2431.

(76) Mitra, M.; Nimir, H.; Demeshko, S.; Bhat, S. S.; Malinkin, S. O.; Haukka, M.; Lloret-Fillol, J.; Lisensky, G. C.; Meyer, F.; Shteinman, A. A.; Browne, W. R.; Hrovat, D. A.; Richmond, M. G.; Costas, M.; Nordlander, E. Nonheme Fe(IV) Oxo Complexes of Two New Pentadentate Ligands and Their Hydrogen-Atom and Oxygen-Atom Transfer Reactions. Inorg. Chem. 2015, 54 (15), 7152-7164.

(77) Kaizer, J.; Klinker, E. J.; Oh, N. Y.; Rohde, J.-U.; Song, W. J.; Stubna, A.; Kim, J.; Münck, E.; Nam, W.; Que, L. Nonheme FeIVO Complexes That Can Oxidize the $\mathrm{C}-\mathrm{H}$ Bonds of Cyclohexane at Room Temperature. J. Am. Chem. Soc. 2004, 126 (2), 472-473.

(78) Nehru, K.; Seo, M. S.; Kim, J.; Nam, W. Oxidative N-Dealkylation Reactions by Oxoiron(IV) Complexes of Nonheme and Heme Ligands. Inorg. Chem. 2007, 46 (1), 293-298.

(79) Serrano-Plana, J.; Oloo, W. N.; Acosta-Rueda, L.; Meier, K. K.; Verdejo, B.; García-España, E.; Basallote, M. G.; Münck, E.; Que, L.; Company, A.; Costas, M. Trapping a Highly Reactive Nonheme Iron Intermediate That Oxygenates Strong $\mathrm{C}-\mathrm{H}$ Bonds with Stereoretention. J. Am. Chem. Soc. 2015, 137 (50), 15833-15842.

(80) Kurahashi, T.; Kikuchi, A.; Shiro, Y.; Hada, M.; Fujii, H. Unique Properties and Reactivity of High-Valent Manganese-Oxo versus Manganese-Hydroxo in the Salen Platform. Inorg. Chem. 2010, 49 (14), 6664-6672.

(81) Gunay, A.; Theopold, K. H. C-H Bond Activations by Metal Oxo Compounds. Chem. Rev. 2010, 110 (2), 1060-1081.

(82) Xue, X.-S.; Ji, P.; Zhou, B.; Cheng, J.-P. The Essential Role of Bond Energetics in C-H Activation/Functionalization. Chem. Rev. 2017, 117 (13), 8622-8648.
(83) Hill, T. L. An Introduction to Statistical Thermodynamics.; Dover Publications: Newburyport, 2012.

(84) Abraham, M. H.; Grellier, P. L.; Prior, D. V.; Duce, P. P.; Morris, J. J.; Taylor, P. J. Hydrogen bonding. Part 7. A scale of solute hydrogen-bond acidity based on log $\mathrm{K}$ values for complexation in tetrachloromethane. J. Chem. Soc., Perkin Trans. 2 1989, No. 6, 699-711.

(85) Abraham, M. H.; Grellier, P. L.; Prior, D. V.; Morris, J. J.; Taylor, P. J. Hydrogen bonding. Part 10. A scale of solute hydrogenbond basicity using $\log \mathrm{K}$ values for complexation in tetrachloromethane. Perkin Trans. 2 1990, No. 4, 521-529.

(86) Snelgrove, D. W.; Lusztyk, J.; Banks, J. T.; Mulder, P.; Ingold, K. U. Kinetic Solvent Effects on Hydrogen-Atom Abstractions: Reliable, Quantitative Predictions via a Single Empirical Equation. J. Am. Chem. Soc. 2001, 123 (3), 469-477.

(87) Weigend, F. Accurate Coulomb-fitting basis sets for $\mathrm{H}$ to $\mathrm{Rn}$. Phys. Chem. Chem. Phys. 2006, 8 (9), 1057-1065.

(88) Weigend, F.; Ahlrichs, R. Balanced basis sets of split valence, triple zeta valence and quadruple zeta valence quality for $\mathrm{H}$ to Rn: Design and assessment of accuracy. Phys. Chem. Chem. Phys. 2005, 7 (18), 3297-3305.

(89) HANDY, N. C.; COHEN, A. J. Left-right correlation energy. Mol. Phys. 2001, 99 (5), 403-412.

(90) COHEN, A. J.; HANDY, N. C. Dynamic correlation. Mol. Phys. 2001, 99 (7), 607-615.

(91) Becke, A. D. Density-functional exchange-energy approximation with correct asymptotic behavior. Phys. Rev. A 1988, 38 (6), 3098-3100.

(92) Neese, F. Software update: the ORCA program system, version 4.0. Wiley Interdiscip. Rev. Comput. Mol. Sci. 2018, 8 (1), e1327.

(93) Johansson, A. J.; Blomberg, M. R. A.; Siegbahn, P. E. M. Quantifying the effects of the self-interaction error in density functional theory: When do the delocalized states appear? II. Ironoxo complexes and closed-shell substrate molecules. J. Chem. Phys. 2008, 129 (15), 154301.

(94) Avila, D. V.; Brown, C. E.; Ingold, K. U.; Lusztyk, J. Solvent effects on the competitive $\beta$-scission and hydrogen atom abstraction reactions of the cumyloxyl radical. Resolution of a long-standing problem. J. Am. Chem. Soc. 1993, 115 (2), 466470 .

(95) Andrae, D.; Häußermann, U.; Dolg, M.; Stoll, H.; Preuß, H. Energy-adjusted ab initio pseudopotentials for the second and third row transition elements. Theoret. Chim. Acta 1990, 77 (2), 123-141.

(96) Grimme, S.; Ehrlich, S.; Goerigk, L. Effect of the damping function in dispersion corrected density functional theory. J. Comput. Chem. 2011, 32 (7), 1456-1465.

(97) van der Walt, S.; Colbert, S. C.; Varoquaux, G. The NumPy Array: A Structure for Efficient Numerical Computation. Comput. Sci. Eng. 2011, 13 (2), 22-30.

(98) McKinney, W. Data Structures for Statistical Computing in Python. Proc. Python Sci. Conf. 2010, 56-61.

(99) Hunter, J. D. Matplotlib: A 2D Graphics Environment. Comput. Sci. Eng. 2007, 9 (3), 90-95.

(100) Pedregosa, F.; Varoquaux, G.; Gramfort, A.; Michel, V.; Thirion, B.; Grisel, O.; Blondel, M.; Prettenhofer, P.; Weiss, R.; Dubourg, V.; Vanderplas, J.; Passos, A.; Cournapeau, D.; Brucher, M.; Perrot, M.; Duchesnay, É. Scikit-learn: Machine Learning in Python. J. Mach. Learn. Res. 2011, 12 (85), 2825-2830.

(101) Virtanen, P.; Gommers, R.; Oliphant, T. E.; Haberland, M.; Reddy, T.; Cournapeau, D.; Burovski, E.; Peterson, P.; Weckesser, W.; Bright, J.; van der Walt, S. J.; Brett, M.; Wilson, J.; Millman, K. J.; Mayorov, N.; Nelson, A. R. J.; Jones, E.; Kern, R.; Larson, E.; Carey, C. J.; Polat, İ.; Feng, Y.; Moore, E. W.; VanderPlas, J.; Laxalde, D.; Perktold, J.; Cimrman, R.; Henriksen, I.; Quintero, E. A.; Harris, C. R.; Archibald, A. M.; Ribeiro, A. H.; Pedregosa, F.; van Mulbregt, P. SciPy 1.0: fundamental algorithms for scientific computing in Python. Nat. Methods 2020, 17 (3), 261-272. 